Article

\title{
Special-Length-Priority Algorithm to Minimize Reinforcing Bar-Cutting Waste for Sustainable Construction
}

\author{
Dongho Lee, Seunghyun Son, Doyeong Kim and Sunkuk Kim * \\ Department of Architectural Engineering, Kyung Hee University, Yongin-si, Gyeonggi-do 17104, Korea; \\ DUL1212@khu.ac.kr (D.L.); seunghyun@khu.ac.kr (S.S.); dream1968@khu.ac.kr (D.K.) \\ * Correspondence: kimskuk@khu.ac.kr; Tel.: +82-31-201-2922
}

Received: 30 June 2020; Accepted: 21 July 2020; Published: 23 July 2020

check for updates

\begin{abstract}
Reinforcing bars (rebar), which have the most embodied carbon dioxide $\left(\mathrm{CO}_{2}\right)$ per unit weight in built environments, generate a significant amount of cutting waste during the construction phase. Excessive cutting waste not only increases the construction cost but also contributes to a significant amount of $\mathrm{CO}_{2}$ emissions. The objective of this paper is to propose a special-length-priority cutting waste minimization (CWM) algorithm for rebar, for sustainable construction. In the proposed algorithms, the minimization method by special and stock lengths was applied. The minimization by special length was performed first, and then the combination by stock length was performed for the remaining rebar. As a result of verifying the proposed algorithms through a case application, it was confirmed that the quantity of rebar was reduced by $6.04 \%$ compared with the actual quantity used. In the case building, a $\mathrm{CO}_{2}$ emissions reduction of 406.6 ton- $\mathrm{CO}_{2}$ and a cost savings of USD 119,306 were confirmed. When the results of this paper are applied in practice, they will be used as a tool for sustainable construction management as well as for construction cost reduction.
\end{abstract}

Keywords: rebar work; cutting waste; minimization; sustainable construction; $\mathrm{CO}_{2}$ emission; cutting stock problem

\section{Introduction}

Building construction and operations accounted for $36 \%$ of global final energy use and nearly $40 \%$ of energy-related carbon dioxide $\left(\mathrm{CO}_{2}\right)$ emissions in 2017 [1]. Concrete and reinforcing steel contribute about $65 \%$ of building greenhouse gases (GHG), $40 \%$ of which are $\mathrm{CO}_{2}$ emissions generated by concrete [2]. Clark and Bradley described that the mean embodied carbon dioxide $\left(\mathrm{ECO}_{2}\right)$ for office buildings is $340 \mathrm{~kg}-\mathrm{CO}_{2} / \mathrm{m}^{2}$, of which the structure accounts for approximately $60 \%$ [3]. In their research report, they suggest $95 \mathrm{~kg}-\mathrm{ECO}_{2} /$ ton for $\mathrm{C} 25 / 30$ concrete and $872 \mathrm{~kg}-\mathrm{ECO}_{2} /$ ton for reinforcing bar (rebar). This suggests that reducing the $\mathrm{ECO}_{2}$ in the structural frame directly produces a GHG reduction. In addition, in terms of the carbon footprint, efforts to reduce the rebar, which has an $\mathrm{ECO}_{2}$ of about 9.2 times that of concrete per unit weight [4], are very important.

In general, rebar cutting waste is estimated in the planning stage to be 3-5\% [5-8] but more than $5 \%$ occurs in the actual construction stage $[5,7-13]$. This is because there is a lack of optimization technology on construction sites [14]. In order to solve this problem, many studies have been conducted to minimize rebar cutting waste [5-25]. Most studies use a stock length called a standard, or market length to make combinations that minimizes cutting waste [8-16,19-25]. In other words, they combine the rebar indicated in the structural drawings using stock lengths held in the rebar shop or plant in order to minimize cutting waste. If the rebar to be ordered by special length is used in the rebar combinations, cutting waste can be further reduced $[5,7,14,17]$. Rebar combinations using special 
lengths and stock lengths can further reduce the cutting waste and $\mathrm{CO}_{2}$ emissions. However, research on the use of special lengths for cutting waste minimization (CWM) in the construction industry is lacking. The study of Porwal and Hewage introduces the concept of special length combination [7], but constraints for minimization by special length (MSpL) are not clearly described. In addition, several studies have suggested the concept of MSpL but lack a detailed explanation of algorithm operation $[7,14,17]$. Additionally, from the viewpoint of sustainable construction, the effect of reducing $\mathrm{CO}_{2}$ emissions through minimization algorithms has not been suggested. Therefore, the objective of this paper is to propose a special-length-priority CWM algorithm for rebar, for sustainable construction.

The study proceeds as shown in Figure 1. First, we describe the originality of this paper and the lessons obtained after reviewing the references on CWM and the cutting stock problem (CSP). Then, we introduce the CWM algorithms, the core content of this paper. We describe in detail the concept of stock and special lengths, the CWM process and algorithms, and MSpL. Next, after applying the proposed algorithms to the case project, we analyze the rebar savings details. In addition, we confirm the $\mathrm{CO}_{2}$ emission and cost reduction effects associated with the rebar quantity reduction. Finally, we discuss the problems, lessons learned, and opportunities for further studies, and we describe the results of this present study.

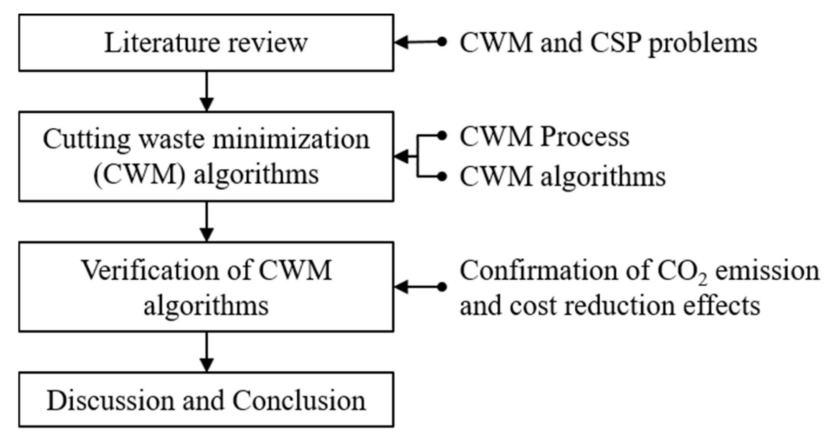

Figure 1. Research process and methodology.

\section{Literature Review of CWM Problems}

Research on CWM began with a study to solve the CSP. The study of the CSP was first mentioned by Kantorovich in 1939 and first published in Management Science in 1960 [26]. The problem consists of determining the best way of cutting a set of large objects into smaller items [27]. In operations research, the CSP is the problem to cut standard-sized pieces of stock material, such as rebar, paper rolls, or sheet metal, into pieces of specified sizes while minimizing the material wasted [28]. Kantorovich provides two examples in his paper to make the CSP easier to understand [26]. Since then, many scholars have conducted research to obtain a solution to the CSP using linear programming [29-42], genetic, or heuristic approaches [43-48].

In the case of rebar CWM, studies using linear programming and/or heuristic algorithms have been conducted [5,7,8,10,12-17,19-25]. In most cases, however, research has been conducted to minimize scrap or cutting waste using stock lengths, and the opportunity to further reduce cutting waste using special lengths has been lost. From the previous studies [5,14], we have confirmed that MSpL reduces cutting waste more than minimization by stock length (MStL). There have been several studies on minimization by special length (MSpL) $[5,7,14,17]$, but various conditions required in practice have not been reflected in algorithms. Furthermore, the application process of MSpL reflecting these conditions was not specifically introduced. In the case of MSpL, variables such as minimum order quantity, rebar lengths for special order, minimum loss rate, and minimum and maximum combination length should be considered in practice. However, in most studies, these conditions were not reflected or sufficiently explained. In the paper of Porwal and Hewage [7], they proposed an algorithm for minimization by market and special lengths using rebar data extracted from building information modeling (BIM). However, detailed descriptions of constraints such as the rebar loss rate and minimum order quantity 
are not clearly described. In other papers $[5,14,17]$, the MSpL concept was introduced, but detailed application processes were not described in their manuscripts.

In this paper, we propose algorithms that perform minimization by stock length on the rebar that is left after MSpL. However, since many scholars are familiar with MStL, MStL is first introduced, and MSpL is discussed later in the manuscript.

\section{Cutting Waste Minimization Algorithms}

\subsection{Definition of Stock and Special Lengths}

Based on the examination of the studies to date, the CWM methods for rebar are largely divided into two types. Minimization by stock length (MStL) $[5,7,8,10,12-17,20-25]$ and MSpL $[5,7,14,17]$. In these two methods, the target loss ratio and minimum quantity can be added as constraints $[5,14,17]$. Figure 2 is an example of combinations of stock lengths and special lengths. In the case of cutting pattern 1 in Figure 2a, two reinforcing bars are combined using a stock length of $12 \mathrm{~m}$, and $0.6 \mathrm{~m}$ of cutting waste or loss occurs, which corresponds to a loss rate of $5 \%$. In the case of cutting pattern $i$, three reinforcing bars are combined and $0.3 \mathrm{~m}$ of cutting waste is generated, which corresponds to a loss rate of $2.5 \%$. If the special length of $11.7 \mathrm{~m}$ is used as shown in Figure 2b, in the same cases there is $0.3 \mathrm{~m}$ of cutting waste, a $2.6 \%$ loss rate, and a loss of zero, respectively. As shown in the examples, when using special lengths, the cutting waste is generally reduced more than with stock lengths.

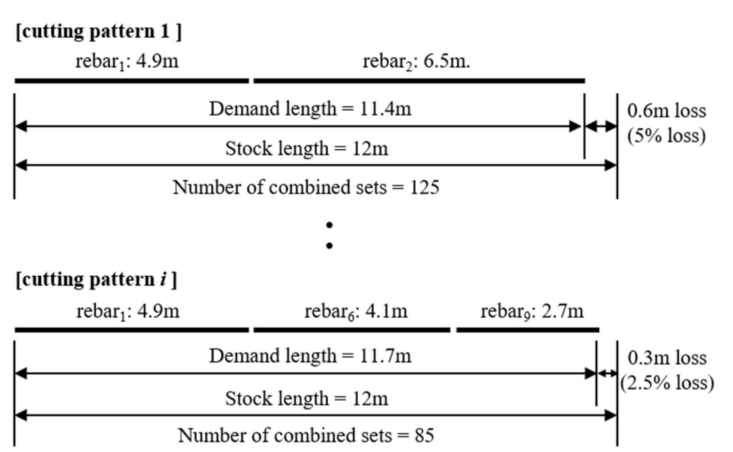

(a)

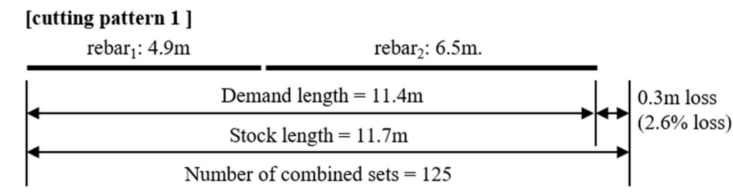

:

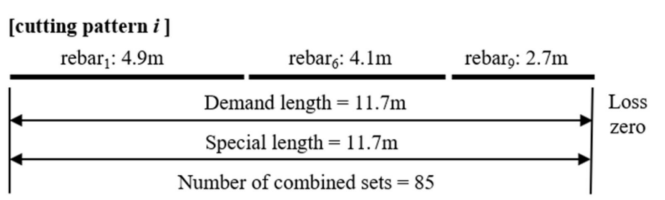

(b)

Figure 2. Combination examples of stock and special lengths: (a) Combination cases of stock lengths; (b) Combination cases of special lengths.

For reference, "special length" means the length determined by the customer's order, not the rebar length sold on the market. For example, stock or market length means the length determined by the producer in regular interval values such as 9, 10, 11, and $12 \mathrm{~m}$, whereas special length includes irregular values such as 8.4, 9.7, and $10.1 \mathrm{~m}$. Although there are differences by country, stock lengths of 7,8 , and up to $12 \mathrm{~m}$ are common in many countries, and when ordering rebar with special lengths, conditions for length, minimum quantity, and delivery time must be satisfied. In the case of Korea, orders must be made in 0.1-m intervals with a minimum quantity of 50 tons and a delivery time of two months or more. For example, rebar with a diameter of $25 \mathrm{~mm}$ and a length of $8.4 \mathrm{~m}$ can be obtained by special order in a quantity of 60 tons and a delivery time of two months.

\subsection{Cutting Waste Minimization Process}

As mentioned earlier, rebar combination by special length provides an opportunity to reduce cutting waste or trim loss more than by stock length. Therefore, unlike the previous studies, which performed CWM by stock length only, the CWM algorithms proposed in this paper perform an MStL on the rebar that is left after performing an MSpL, as shown in Figure 3. 


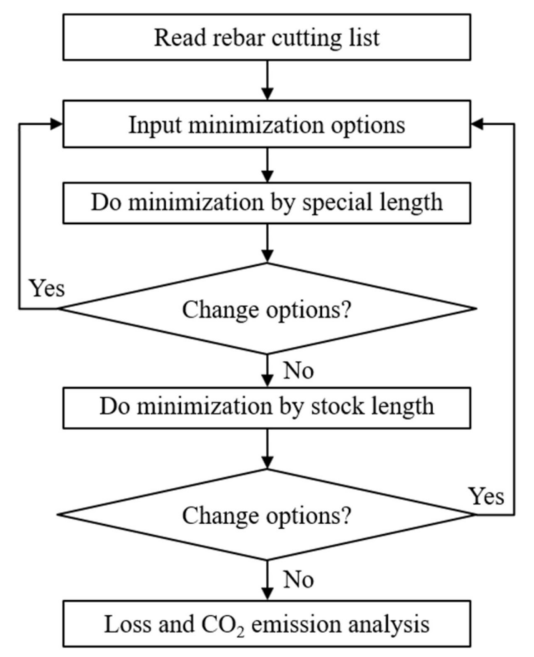

Figure 3. Cutting waste minimization process.

Figure 3 is described briefly as follows: (1) Read the rebar cutting list from the BIM [7] or computerized IPD system [17]; (2) Input options such as minimum and maximum lengths of rebar to be ordered, target loss rate, and minimum rebar quantity to be combined; (3) Execute the MSpL that satisfies the input options; (4) If the desired solution is not derived, decide whether to perform the MSpL again after mitigating options or perform an MStL; (5) If the desired solution cannot be derived from the MStL, decide whether to perform the optimization again by changing options. Otherwise, the process is terminated after analyzing the cutting waste and $\mathrm{CO}_{2}$ emissions.

\subsection{Cutting Waste Minimization Algorithm}

In general, $\mathrm{CWM}$ is performed for stock lengths using the objective function shown in Equation (1) as introduced in several studies $[5,14,17]$. This is a mathematical formulation that minimizes the difference between the length of the cutting pattern $\left(l_{i}\right)$ and the stock length $\left(L s t_{i}\right)$ obtained by combining multiple rebars. In this case, the constraints of Equations (2) to (4) must be satisfied. For reference, in Equation (2), $l_{i}$ corresponds to the demand length in Figure $2 \mathrm{a}$, and $r_{1}, r_{2}, . ., r_{n}$ correspond to rebar 1 , rebar 2 , rebar . Equation (3) is not necessary if a single stock length is used, but it must be satisfied if several stock lengths are used. In the case of construction sites, the conditions of Equation (3) are generally valid because rebar of multiple market lengths can be purchased.

$$
\begin{aligned}
& \text { Minimize } f\left(X_{i}\right)=\sum_{i=1}^{N}\left(L_{s t} n_{i}-l_{i} n_{i}\right) / L_{s} t_{i} n_{i} \\
& \text { Subject to } l_{i} \leq L s t_{i}, l_{i}=r_{1}+r_{2}+\ldots+r_{n} \\
& L_{\text {min }} \leq \text { Lst }_{i} \leq L_{\max } 0 \\
& <n_{i} \text {, integer, } \mathrm{i}=1,2, \ldots, \mathrm{N}
\end{aligned}
$$

Here,

$L s t_{i}=$ Stock length of cutting pattern $\mathrm{i}(\mathrm{m})$

$l_{i}=$ Length of cutting pattern i obtained by combining multiple rebars, demand lengths $(\mathrm{m})$

$n_{i}=$ Number of rebar combinations with the same cutting pattern $\mathrm{i}$

$r_{i}=$ Length of combined rebar $(\mathrm{m})$

$L_{\min }=$ Minimum length of rebar to be ordered $(\mathrm{m})$

$L_{\max }=$ Maximum length of rebar to be ordered $(\mathrm{m})$.

So far, most rebar optimization studies in the construction sector have been conducted for MStL. This is because materials such as rebar, structural steel, pipes, and timber are supplied by the 
manufacturer in market lengths. If the target loss rate is added as a constraint to the CWM, Equation (5) should be used. In this case, the combination is executed only when the loss rate $(\varepsilon)$ caused by the cutting pattern is less than or equal to the target loss rate $\left(\varepsilon_{t}\right)$. When MSpL is performed, the loss rate can be further reduced but many algorithms have focused on MStL because of the complexity of the optimization algorithms.

$$
\varepsilon=\frac{L s t_{i}-l_{i}}{L s t_{i}} \leq \varepsilon_{t}
$$

Here,

$\varepsilon_{t}=$ Target cutting waste or loss rate $(\%)$

$\varepsilon=$ Cutting waste or loss rate $(\%)$.

\subsection{Minimization by Special Length}

The mathematical formulation of CWM by special length is described in Equations (7)-(11), which is similar with previous studies $[5,7,14]$. Special lengths $\left(L s p_{i}\right)$ that satisfy constraints such as the target loss (scrap or waste) rate $\left(\varepsilon_{t}\right)$ and minimum quantity for special order $\left(Q_{s o}\right)$ must be searched. In this case, the special length must be within the range of minimum $\left(L_{\min }\right)$ and maximum $\left(L_{\max }\right)$ lengths where special orders are possible.

$$
\begin{gathered}
\text { Minimize } f\left(X_{i}\right)=\sum_{i=1}^{N}\left(L s p_{i} n_{i}-l_{i} n_{i}\right) / L s p_{i} n_{i} \\
\text { Subject to } l_{i} \leq L s p_{i}, l_{i}=r_{1}+r_{2}+\ldots+r_{n} \\
L_{\min } \leq L s p_{i} \leq L_{\max } \\
\varepsilon=\frac{L s p_{i}-l_{i}}{L s p_{i}} \leq \varepsilon_{t} \\
Q_{\text {so }} \leq Q_{\text {total }}, 0 \\
<n_{i}, \text { integer, } \mathrm{i}=1,2, \ldots, \mathrm{N}
\end{gathered}
$$

Here,

$l_{i}=$ Length of cutting pattern i obtained by combining multiple rebars, demand lengths (m)

$L s p_{i}=$ Special length of cutting pattern $i$ that satisfies the target loss rate $(\mathrm{m})$

$L_{\min }=$ Minimum length of rebar to be ordered $(\mathrm{m})$

$L_{\max }=$ Maximum length of rebar to be ordered $(\mathrm{m})$

$n_{i}=$ Number of rebar combinations with the same cutting pattern $\mathrm{i}$

$r_{i}=$ Length of combined rebar $(\mathrm{m})$

$\varepsilon=$ Cutting waste or loss rate $(\%)$

$\varepsilon_{t}=$ Target cutting waste or loss rate (\%)

$Q_{\text {total }}=$ Total combined rebar quantity (ton)

$Q_{s o}=$ Minimum rebar quantity to be special ordered (ton).

For example, in the case where the loss rate is less than $2 \%$, the length is between 8 and $12 \mathrm{~m}$ at intervals of $0.1 \mathrm{~m}$, but the total quantity $\left(Q_{\text {total }}\right)$ of the same length that will be more than 50 tons is searched. The MSpL that satisfies these conditions proceeds with the process shown in Figure 4. The minimization process in that figure is described in pseudocode, as follows:

(1) After the rebar cutting list is read, in which the number of reinforcing bars by diameter and length is counted, it is sorted in descending order with length and number priority. This is for efficient performance of the quantity-priority combination.

(2) Options such as the maximum $\left(L_{\max }\right)$ and minimum $\left(L_{\min }\right)$ lengths of rebar to be ordered, target loss rate $\left(\varepsilon_{t}\right)$, and minimum rebar quantity $\left(Q_{s o}\right)$ to be special ordered are entered. If the target 
loss rate is not entered, the combination that satisfies the condition of $Q_{s o}$ with a special length priority is executed by default.

(3) The rebar combination $\left(l_{i}\right)$ that satisfies $L_{\min } \leq L s p_{i} \leq L_{\max }$ for rebar of the same diameter is executed in descending order from the maximum length $\left(L_{\max }\right)$ of rebar to be ordered. If $\left(L s p_{i}-l_{i}\right) / L s p_{i} \leq \varepsilon_{t}$ is satisfied, the next combination $(i=i+1)$ is executed until the end of the list after saving the result of combination, or the combination is performed until the loss rate condition is satisfied. This is because executing the combination in descending order from the maximum length is effective in performing the quantity-priority combination, as described in step (1).

(4) Next, the total quantity of combined rebar is calculated by Equation (12).

$$
Q_{\text {total }}=w \sum_{i=1}^{N} L s p_{i} n_{i}
$$

here, $w=$ unit weight of combined rebar per meter (ton $/ \mathrm{m})$.

(5) If $Q_{s o} \leq Q_{\text {total }}$ is not satisfied, MSpL is repeated while $L s p_{i}$ is decreased by $0.1 \mathrm{~m}$ until $L s p_{i} \leq L_{\text {min }}$ is satisfied. If a solution that satisfies the constraints is not found in the process so far, it should be decided whether to perform the minimization again after alleviating the combination conditions. Otherwise, MStL must be subsequently performed.

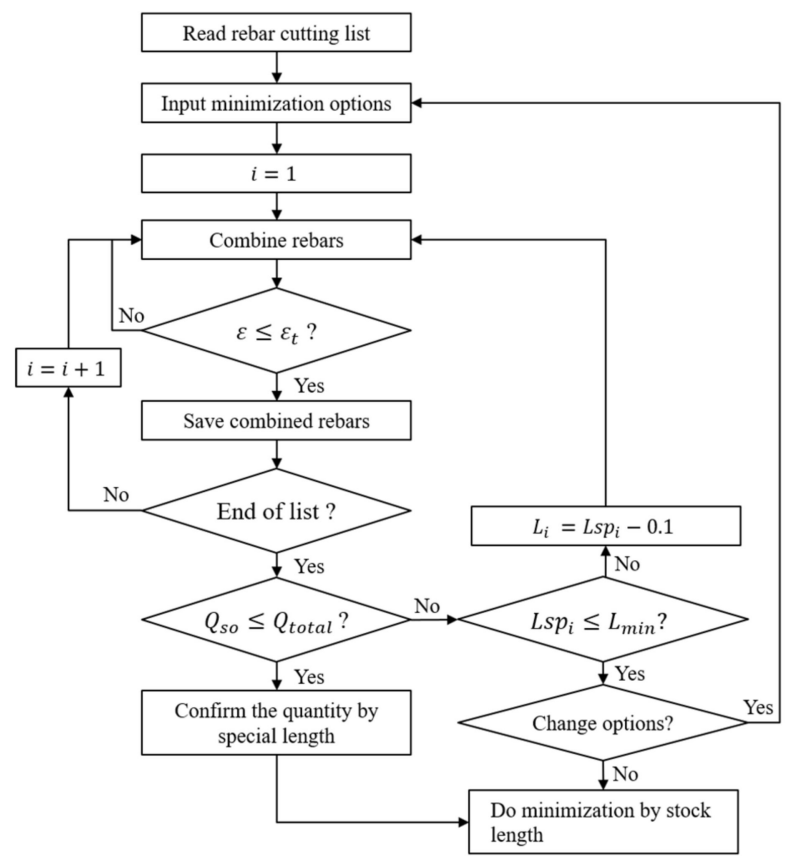

Figure 4. Minimization process by special length.

If $Q_{s o} \leq Q_{\text {total }}$ is satisfied, the quantity of special length is determined and MStL is executed for the remaining rebar. As all of the rebar is not combined by special length, minimization is performed with stock lengths for the remaining ones.

\section{Verification of CWM Algorithms}

\subsection{Brief Description of the Case Project}

The effectiveness of CWM algorithms by stock and special lengths described so far should be verified through case application. To this end, the case project shown in Table 1 was selected in this study. This is a commercial building project constructed in Seoul, Korea, with a total floor area of $66,644 \mathrm{~m}^{2}$, three basement levels, and 20 floors above ground. The site area of the case project is not 
large enough for rebar work on site. Moreover, considering the quality, time, and safety, the rebar was supplied from the plant.

Table 1. Description of the case project.

\begin{tabular}{ll}
\hline Description & Contents \\
\hline Location & Seoul, Korea \\
Site area & $8832 \mathrm{~m}^{2}$ \\
Building area & $3970 \mathrm{~m}^{2}$ \\
Total floor area & $66,644 \mathrm{~m}^{2}$ \\
No. of floors & B3 to F20 \\
Structure & Basement: SRC \\
& Superstructure: RC \\
\hline
\end{tabular}

Reviewing the structure of the case building, the underground structure is steel reinforced concrete (SRC) and the superstructure is reinforced concrete (RC). In addition, the first and second floors are designed as a column-and-beam structure, and as shown in Figure 5, from the 3rd floor to the 20th floor, it is designed as a flat slab structure. That is, the case building includes three types of structures. For effective verification of the proposed CWM algorithms, as shown in Figure 5, the case application is performed on the flat slab structure from the 3rd floor to the 20th floor, which is the largest part of the building.

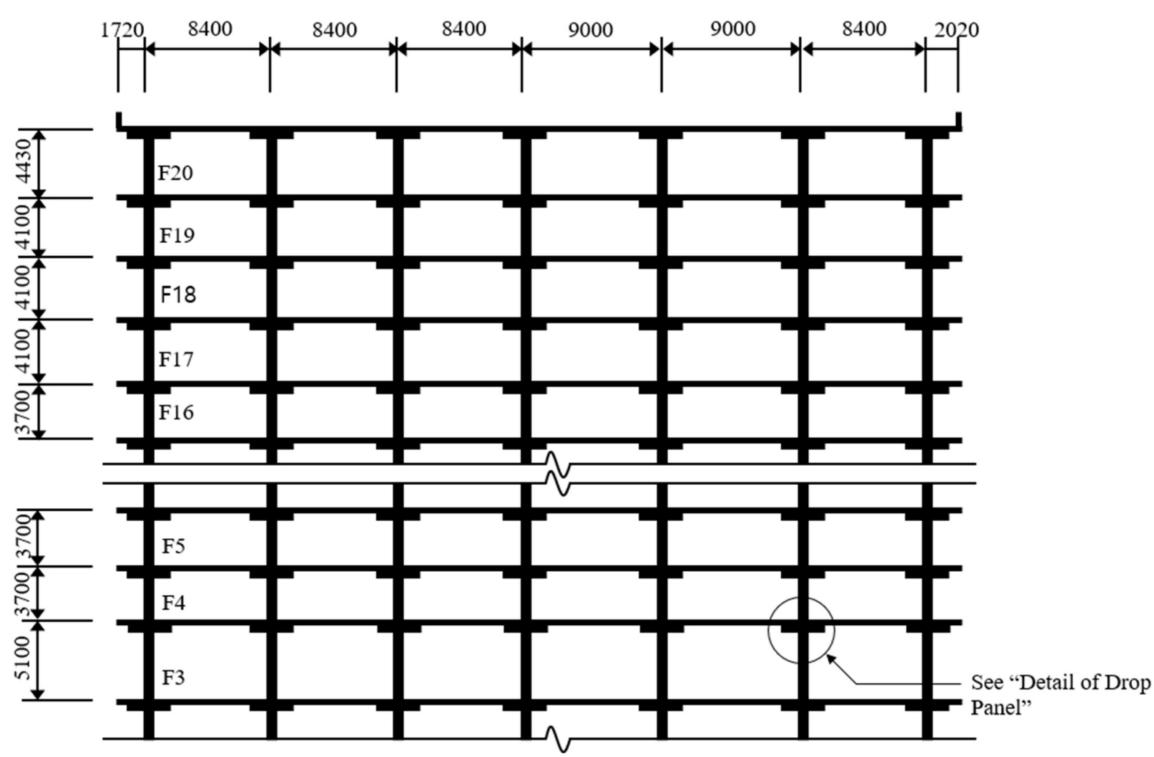

Figure 5. Structural frame of the case building.

The flat slab structure of the case project is composed of columns, slabs, and drop panels. Therefore, as shown in Figures 5 and 6, the top of each column is reinforced by drop panels. Figure 6a is the sectional detail of the drop panel that is most frequently applied to the case structure, and below the drop panel, 11-D16s are reinforced at 300-mm intervals as shown in Figure 6b. In the case of the slab part, D13 is installed at 300-mm intervals in both directions on the upper and lower sides as shown in Figure 6c. Furthermore, at the top of the drop panel, D16 is additionally reinforced at 300-mm intervals over the width of the column strip. As shown in Figure $6 \mathrm{a}$, the slab thickness is $250 \mathrm{~mm}$, and the drop panel thickness is $450 \mathrm{~mm}$ (200 mm thicker than the slab). For reference, the cross-section of deformed bars is variously marked in many countries as $\mathrm{Y}, \mathrm{H}, \mathrm{D}$, etc. In the case of this paper, it is denoted by D (Deformed bar), which is commonly used in Korea. 


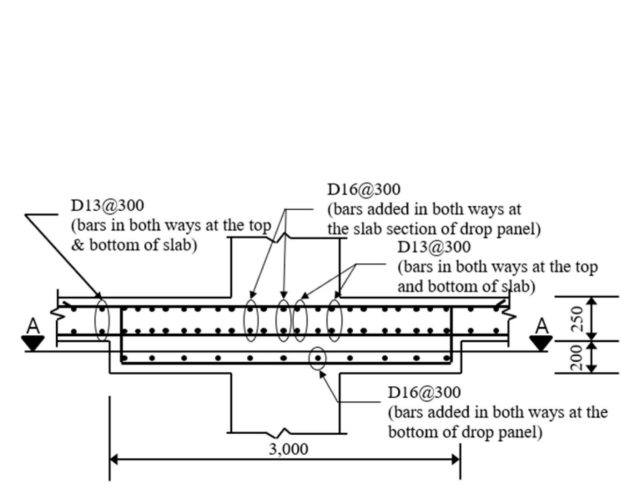

(a)

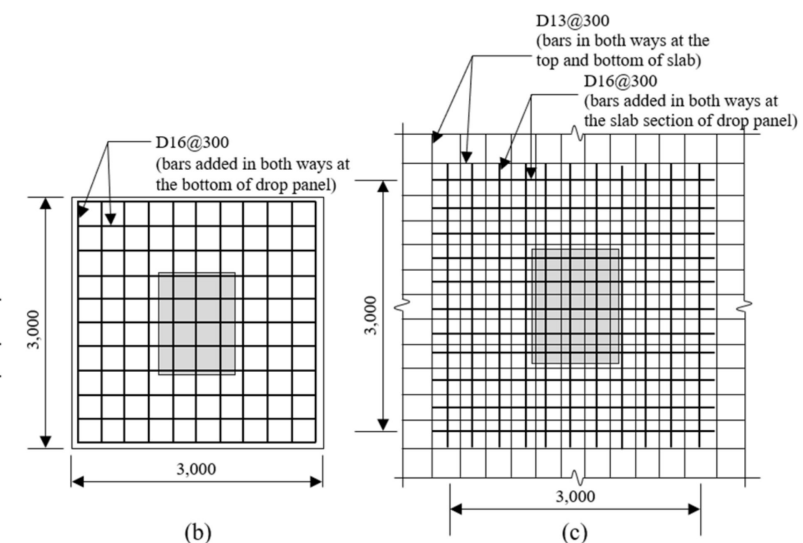

(b)

(c)

Figure 6. Detail of drop panel reinforcement: (a) Sectional detail of drop panel; (b) Section A-A; (c) Detail at the slab part of drop panel.

For the columns of the case project, as shown in Figures 5 and 7, all of them, including C3, have four sections with different reinforcements, such as $900 \times 1200,800 \times 1000$, and $600 \times 1000$, from F3 to F20. This is because the design was optimized according to the change in the load condition of each floor. As shown in Figure 7, the main bars are designed to have 26, 16, and 14 deformed bars with a diameter of $25 \mathrm{~mm}$, gradually decreasing in number. Additionally, the sizes and combinations of tie bars and hoops designed for buckling vary from 5-D10 at F3 to F10, to 2-D10 at F14 to F20, as shown in Figure 7. For reference, the 5-D10 tie bars and hoops consist of five deformed tie bars and one hoop with a diameter of $10 \mathrm{~mm}$. The columns shown in Figures 5 and 7 are connected by mechanical couplers, so there is no splice lapping. Therefore, according to the cross-sectional change, the rebar that is installed continuously in the upper and lower columns is connected by couplers, but the rest of it is anchored to the upper column. The case building has less rebar than the structure size because, in order to reduce the cross-sections of the structural members, super-high-tensile deformed (SHD) bars with a yield strength of $500 \mathrm{MPa}$ were used for D10 and D13, and ultra-high-tensile deformed (UHD) bars with a yield strength of $600 \mathrm{MPa}$ were used for D16, D19, and D25.

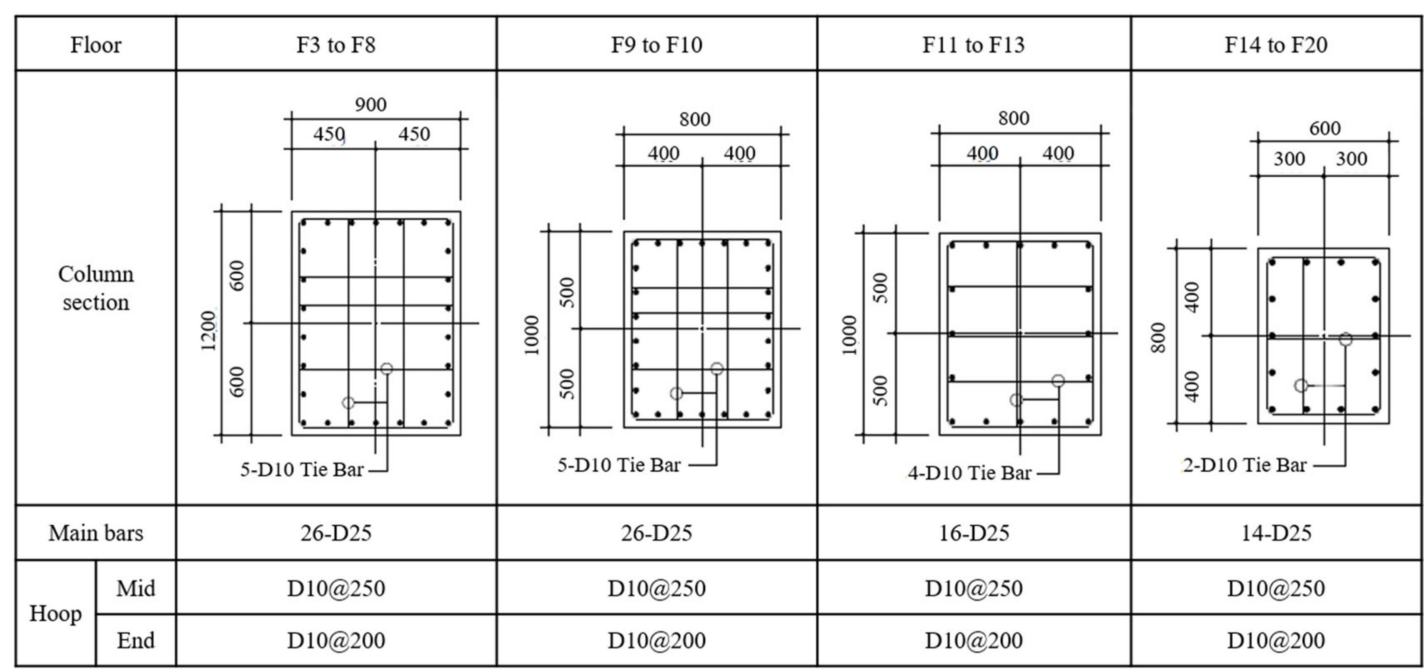

Figure 7. Rebar details of column C3.

\subsection{Application of CWM Algorithms}

In this study, for the verification of the proposed algorithm, rebar combinations were performed on structural frames from F3 to F20. The rebar cutting list generated from the bar-bending schedule was used for rebar information. At the case site, various diameters of rebar were used. For example, in the case of the column in Figure 7, 25-mm-diameter rebar was used for the main bar, and 10-mm-diameter 
rebar was used for the hoop. Tables 2 and 3 show the combination results of the CWM algorithms for the main bars of all of the columns.

Table 2. Combination report for special lengths of 25-mm diameter rebar.

\begin{tabular}{|c|c|c|c|c|c|c|}
\hline \multicolumn{7}{|c|}{ Combination Report for Special Lengths } \\
\hline \multirow{2}{*}{\multicolumn{2}{|c|}{$\begin{array}{l}\text { Diameter }(\mathrm{mm})=25 \\
\text { Combination } \\
\text { conditions }\end{array}$}} & \multicolumn{5}{|c|}{ Reference files $=$ proj101_bcl.dat } \\
\hline & & \multicolumn{3}{|c|}{$\begin{array}{l}\text { Min. length }(\mathrm{m})=6.0 \\
\text { Min. weight }(\text { ton })=50\end{array}$} & \multicolumn{2}{|c|}{$\begin{array}{c}\text { Max. length }=10.0 \\
\text { Max. loss rate }(\%)=3.0\end{array}$} \\
\hline $\begin{array}{l}\text { Cutting } \\
\text { Pattern }\end{array}$ & $\begin{array}{l}\text { No. of } \\
\text { rebars }\end{array}$ & $\begin{array}{l}\text { Combined } \\
\text { Length }(\mathrm{m})\end{array}$ & $\begin{array}{c}\text { Order } \\
\text { Length }(\mathrm{m})\end{array}$ & Combined Weight (ton) & $\begin{array}{l}\text { Order Weight } \\
\text { (ton) }\end{array}$ & $\begin{array}{c}\text { Loss Rate } \\
(\%)\end{array}$ \\
\hline S1 & 6121 & 7400 & 7400 & 176.20 & 176.20 & 0.00 \\
\hline S2 & 1196 & 9200 & 9200 & 42.80 & 42.80 & 0.00 \\
\hline S3 & 526 & 8.530 & 9200 & 17.45 & 18.82 & 7.85 \\
\hline Sum & & & & 236.45 & 237.82 & 0.58 \\
\hline
\end{tabular}

Table 3. Combination report for stock lengths of 25-mm-diameter rebar.

\begin{tabular}{|c|c|c|c|c|c|c|}
\hline \multicolumn{7}{|c|}{ Combination Report for Stock Lengths } \\
\hline \multirow{2}{*}{\multicolumn{2}{|c|}{$\begin{array}{c}\text { Diameter }(\mathrm{mm})=25 \\
\text { Combination conditions }\end{array}$}} & \multicolumn{5}{|c|}{ Reference files $=$ proj101_bcl.dat } \\
\hline & & \multicolumn{3}{|c|}{$\begin{array}{l}\text { Min. length }(\mathrm{m})=6.0 \\
\text { Min. weight }(\text { ton })=\end{array}$} & \multicolumn{2}{|c|}{$\begin{array}{l}\text { Max. length }=10.0 \\
\text { Max. loss }(\%)=3.0\end{array}$} \\
\hline $\begin{array}{l}\text { Cutting } \\
\text { Pattern }\end{array}$ & $\begin{array}{l}\text { No. of } \\
\text { Rebars }\end{array}$ & $\begin{array}{l}\text { Combined } \\
\text { Length }(\mathrm{m})\end{array}$ & $\begin{array}{c}\text { Stock } \\
\text { Length }(\mathrm{m})\end{array}$ & Combined Weight (ton) & $\begin{array}{l}\text { Stock Weight } \\
\text { (ton) }\end{array}$ & $\begin{array}{l}\text { Loss Rate } \\
\quad(\%)\end{array}$ \\
\hline N1 & 48 & 8.860 & 9.000 & 1.65 & 1.68 & 1.58 \\
\hline Sum & & & & 1.65 & 1.68 & 1.58 \\
\hline
\end{tabular}

Table 2 shows the results of minimization by MSpL according to Equations (6) to (11), and the final loss rate, i.e., cutting waste rate, was calculated to be $0.58 \%$. A detailed description of Table 2 is as follows: (a) Combination is performed on the 25-mm rebar in the bar-cutting list file named "proj101_bcl.dat": (b) The minimum quantity of special length is 50 tons after combination for rebar with a minimum length of $6.0 \mathrm{~m}$ and a maximum length of $10.0 \mathrm{~m}$, and the maximum loss rate is not specified as 3.0\%; (c) Cutting pattern S1 has the same combined and order lengths of $7.4 \mathrm{~m}$, so the loss rate is zero for the order quantity of 176.2 tons; (d) The combined and order lengths of the cutting pattern S2 are equal to $9.2 \mathrm{~m}$, so the loss rate is zero for the order quantity of 42.8 tons; (e) Finally, in cutting pattern S3, the combined length is $8.53 \mathrm{~m}$, but in order to satisfy the minimum order weight of 50 tons, 18.82 tons must be ordered with a length of $9.2 \mathrm{~m}$, in which case the loss rate is increased to $7.85 \%$. However, as shown in Table 2, the quantity of S3 is relatively small compared with S1 and S2. Therefore, the loss rate of the final MSpL is $0.58 \%$, which corresponds to 1.37 tons of cutting waste.

For reference, in the case structural frame, 25-mm-diameter rebar was used for the columns only. Additionally, there were not many cutting patterns because there were many main rebars of the same length. In other words, as shown in Figure 5, the lengths of the main rebars of all of the columns on the same floor were the same and the length was changed according to the change in floor height. The total number of main rebars in the case frame was 15,734, which were identified in five lengths.

Table 3 shows the results of MStL by Equations (1) to (4), and the final loss rate was calculated as $1.58 \%$. In Table 2, the cutting pattern is combined into one because it is performed on the remaining rebar after combination by special length. For cutting pattern N1, the combined length is $8.86 \mathrm{~m}$ and the stock length is $9.0 \mathrm{~m}$. The combined and stock weight are 1.65 and 1.68 tons, respectively, and the loss rate is $1.58 \%$. For reference, in the case of MStL, the combination conditions are the same as for MSpL but the minimum weight is not specified. This is because it is assumed that there is a sufficient quantity in stock. 
Comparing the results of Tables 2 and 3, the minimization results by special length have a lower loss rate than by stock length. This is because combination by special length is performed to further reduce the loss rate.

Table 4 shows the results of applying CWM algorithms to all types of rebar used in the case structural frame in Figures 5-7. Five diameters of rebar were used, and a total loss rate of $0.96 \%$ was calculated. The total quantity of rebar required for construction is 1.807 .45 tons, and the quantity to be supplied in special and stock lengths is 1.824 .75 tons. The loss rate is different for each diameter of rebar depending on the design characteristics of the structural member in which each rebar is used. The details are as follows.

Table 4. Combination report by rebar size.

\begin{tabular}{cccccccc}
\hline Description & Unit & D10 & D13 & D16 & D19 & D25 & Sum \\
\hline Combined weight (C) & ton & 335.62 & 899.93 & 259.94 & 73.86 & 238.10 & 1.807 .45 \\
Supply weight (S) & ton & 338.29 & 906.03 & 264.01 & 76.92 & 239.50 & 1.824 .75 \\
\hline Loss rate (S-C)/S & $\%$ & 0.80 & 0.68 & 1.57 & 4.14 & 0.59 & 0.96 \\
\hline
\end{tabular}

D10, D13, and D16 are mostly rebars that are repeatedly used in various structural members such as slabs, staircase walls, stairs, hoops, and drop panels. In those applications, many rebars of the same length are placed in the same type of structural members. In addition to these characteristics, small-diameter rebar left after cutting for primary use can be used for various other purposes. For example, they can be used as diagonal bars for crack reinforcement, reinforcement of openings, etc. Therefore, the cutting waste rate is lower than that of large-diameter rebar. Moreover, the combined weight was sufficient to cover the various cutting patterns, so MSpL and MStL using the CWM algorithms were performed smoothly.

In the case of D19, MStL was performed because there was no combination that met the minimum weight for a special order (50 tons). As a result, the cutting waste rate increased. Lastly, in the case of D25, most of the rebar was combined with the MSpL algorithm, as described in Tables 2 and 3, so the cutting waste rate was the lowest.

\subsection{Comparison of Actual and Optimized Rebar Quantities}

In order to verify the effectiveness of CWM algorithms, actual and optimized rebar quantities must be compared. As shown in Table 5, the actual quantity of rebar in the case structural frame is 1.942.05 tons and the quantity optimized by the CWM algorithms is 1.824 .75 tons. As a result, 117.30 tons were saved, which is $6.04 \%$ of the actual quantity. It can be seen from this table that the reduction rate differs significantly for each diameter of rebar.

Table 5. Comparison of actual and optimized rebar quantities.

\begin{tabular}{cccccccc}
\hline Description & Unit & D10 & D13 & D16 & D19 & D25 & Sum \\
\hline Actual (A) & ton & 377.00 & 952.43 & 276.00 & 87.80 & 248.82 & 1.942 .05 \\
Optimized (O) & ton & 338.29 & 906.03 & 264.01 & 76.92 & 239.50 & 1.824 .75 \\
\hline Quantity reduction (A-O) & ton & 38.71 & 46.40 & 11.99 & 10.88 & 9.32 & 117.30 \\
Reduction rate (A-O)/A & $\%$ & 10.27 & 4.87 & 4.34 & 12.39 & 3.75 & 6.04 \\
\hline
\end{tabular}

As described above, small-diameter rebar had more secondary use after cutting. Therefore, it is common that less cutting waste is generated with small-diameter rebar. However, in Table 5, the $10.27 \%$ reduction rate for D10 is higher than that of D13 and D16, which means that the loss rate of the actual quantity of rebar is higher than the optimized one. The high quantity reduction rate calculated after optimization by the CWM algorithms means that the loss rate of the actual rebar quantity is high. The reason is presumed to be a problem with the rebar work management. In addition, Table 5 
confirms a relatively small loss rate for D13 and D16. This is because there are many rebars with the same lengths repeatedly used in structural members such as slabs, staircase walls, and drop panels.

In the case of D19, it is confirmed that the cutting waste is increased because the quantity required for the work is relatively small and there are not many rebars of the same length placed repeatedly. However, it is confirmed that a cutting waste reduction of $12.39 \%$ can be obtained using the CWM algorithms proposed in this study. Lastly, in the case of D25, it is used for the main rebar of the columns, and it is relatively easy to manage the rebar to reduce cutting waste because there are not many changes in length. Therefore, it is confirmed that the quantity reduction of this rebar by optimization is $3.75 \%$, which is smaller than that of the other types of rebar, as shown in Table 5. For reference, when the reduced rebar quantity of 117.3 tons is converted into money, it is about USD 98,976 including material, cutting and bending, and placement costs.

\section{4. $\mathrm{CO}_{2}$ Emission Reduction Effects}

When using the CWM algorithms proposed in this study, the contribution to sustainable construction should be confirmed. For this, Table 6 shows the quantitative calculation of the $\mathrm{CO}_{2}$ emissions for rebar saved by the algorithms. Substituting 3.466 ton- $\mathrm{CO}_{2} /$ ton [49], the unit $\mathrm{CO}_{2}$ emissions of high-tensile deformed bar published by the Korea Institute of Construction Technology (KICT), show that the $\mathrm{CO}_{2}$ emissions from the actual rebar work and the optimized result are calculated to be 6.731 .15 and 6.324.58 tons, respectively. For reference, the LCI DB (Life Cycle Inventory Database) varies by country, and this study cited the data presented in the research report of the government-funded research institute, KICT. In addition, because the LCI DB for SHD and UHD used in the case project has not been officially provided, the unit $\mathrm{CO}_{2}$ emission data for high-tensile deformed bar are cited in this paper.

Table 6. Calculation of $\mathrm{CO}_{2}$ emission reduction effect.

\begin{tabular}{cccc}
\hline Description & Quantity (ton) & Unit $\mathbf{C O}_{\mathbf{2}}$ Emission (ton-CO $\mathbf{C O}_{2}$ /ton) & Amount (ton-CO $\mathbf{C O}_{\mathbf{2}}$ ) \\
\hline Actual (A) & 1.942 .05 & 3.466 & 6.731 .15 \\
Optimized (O) & 1.824 .75 & 3.466 & 6.324 .58 \\
\hline Reduction effect (A-O) & 117.30 & & 406.60 \\
\hline
\end{tabular}

As shown in Table 6, when the CWM algorithms are applied, it can be seen that the case project has a $\mathrm{CO}_{2}$ emission reduction of 406.60 tons which is equivalent to $6.04 \%$ of the structure. As mentioned in the introduction, in the case of buildings, the structure accounts for about $65 \%$ of building GHGs [3]. Considering this reference, there is a $\mathrm{CO}_{2}$ emission reduction of $3.93 \%$ based on the whole building. From a carbon footprint point of view, the embodied $\mathrm{CO}_{2}$ per unit weight or volume of rebar is about 9.02 times that of concrete [4]; therefore, the $\mathrm{CO}_{2}$ emission reduction produced by the $\mathrm{CWM}$ algorithms has a great effect on sustainable construction.

It is necessary to confirm the cost reduction effect by converting the $\mathrm{CO}_{2}$ emission reduction effect to the carbon price. To this end, the cost savings of USD 20,330 can be confirmed when applying the Korean carbon transaction price of USD 50/ton- $\mathrm{CO}_{2}$ [50] announced by the Carbon Disclosure Project (CDP). When this amount is added to the previously calculated savings of USD 98,976 in construction cost, a total savings of USD 119,306 is confirmed. Similar to LCI DB, the annual price of carbon traded by CDP varies by country. According to CDP data, in the case of Korea, the price was USD 64/ton- $\mathrm{CO}_{2}$ in 2016 and USD 50/ton- $\mathrm{CO}_{2}$ in 2017, which is USD 14/ton- $\mathrm{CO}_{2}$ lower than the previous year.

The proposed algorithms were applied to the 3rd to 20th floors, designed as a flat slab structure, which is part of the case project. The amount of rebar used in the entire structural frame of the case project was found to be 3.444 .06 tons. Therefore, if the CWM algorithms proposed in this study are applied to the entire structural frame, greater $\mathrm{CO}_{2}$ emission and cost reductions are expected. 


\section{Discussion}

In this study, as shown in Figure 3, we proposed an algorithm that performs MStL on the rebar that remains after special length minimization. With this algorithm, cutting waste or trim loss is further reduced because, as illustrated in Figure 2, the special length is combined at 0.1-m intervals, unlike the stock length, which is generally combined at 1-m intervals. This is also confirmed by the results shown in Tables 2 and 3.

Through this study, we confirmed that additional in-depth studies are needed on these two issues. First, it is possible to combine all of the rebar for one project at the same time, but the results may not be practical. For example, rebar placed on the first and 20th floors can be combined. In this case, the inventory management cost may be high because there is a significant time difference between the use of rebar on the 1st floor and the use of the remaining rebar on the 20th floor. Therefore, the combination condition for rebar to be used within a certain time must be added. For example, the condition for performing a combination of rebar to be used within two weeks should be added. So far, most of the papers related to CSP do not consider the time factor. If the required rebar information can be obtained automatically from the BIM [7] or from an integrated project delivery system [17] linked to the schedule, this problem can be easily solved.

Existing CSP-related studies, including this paper, use original rebar information generated after the structural design. In this case, there are different amounts of rebar of various lengths, and numerous combinations are repeated to search for solutions. Additionally, as mentioned above, rebar scattered in various locations are combined. In addition to cutting patterns that are difficult to apply practically, cutting waste rates cannot be reduced below a certain level [5]. However, it was confirmed that near-zero cutting waste could be achieved by realigning the rebar in the drawings created after the structural design in special lengths using heuristic algorithms. It was also confirmed that heuristic algorithms would be more efficient than mathematical algorithms in performing rebar realignment. Therefore, further studies on the rebar alignment algorithm for near-zero cutting waste should be performed for sustainable construction.

During the case study, it was confirmed that significant efforts have been made from the structural design stage to increase the productivity of rebar work and reduce the rebar loss rate. For example, it is common for some Korean companies to use 500- or 600-MPa super- or ultra-tensile bars instead of 400-MPa high-tensile deformed bar, and to use couplers to connect rebar more than $20 \mathrm{~mm}$ in diameter. The goal of near-zero cutting waste for sustainable construction is expected to be achieved if heuristic rebar alignment algorithms are applied along with these efforts.

\section{Conclusions}

Efforts to reduce carbon and climate change risk are being carried out globally and in all industries. In particular, rebar, which has the most $\mathrm{ECO}_{2}$ per unit weight in built environments, generates a significant amount of cutting waste in the construction phase. Therefore, there is not only the cost of rebar construction but also a considerable amount of $\mathrm{CO}_{2}$ emissions to be expected. To solve this issue, we proposed rebar CWM algorithms for sustainable construction. The effectiveness of the proposed algorithms was verified through a case project, and the following results were obtained.

First, in the case of the optimization of D25 rebar, the cutting waste rate for special lengths was $0.58 \%$, whereas that for stock lengths was $1.58 \%$. This proved the assumption that combination by special length reduced the loss rate more than combination by stock length.

Furthermore, although the actual quantity of rebar put into the case project was 1942.05 tons, the quantity optimized by the proposed algorithms was 1824.75 tons, which represented a quantity reduction of 117.3 tons. This corresponds to $6.04 \%$ of the actual quantity and a savings of USD 98,976 in construction costs.

In addition, $\mathrm{CO}_{2}$ emissions by the proposed optimization algorithms compared with actual emissions had a reduction of 406.6 ton- $\mathrm{CO}_{2}$. This corresponds to a $\mathrm{CO}_{2}$ emission reduction of $3.93 \%$ based on the whole building, reflecting that the structure accounts for about $65 \%$ of building GHGs [3]. 
This is a savings of USD 20,330 based on the carbon trade price in Korea, and a total savings of USD 119,306 , including a reduction in construction costs. The quantity of rebar used in the entire building of the case project, including the flat slab structure on the 3rd to 20th floors, was found to be 3444.06 tons. If the proposed algorithms had been applied to the entire building, further $\mathrm{CO}_{2}$ and cost savings would have been expected.

These results confirmed that the proposed CWM algorithms worked as an effective tool for sustainable construction. During this study, it was observed that near-zero cutting waste could be achieved by realigning the rebar in the structural drawings to special lengths. In other words, it was observed that repositioning rebar of a certain length while satisfying the structural design criteria might significantly reduce cutting waste. In order to do this efficiently, heuristic algorithms of a new concept rather than the mathematical algorithms proposed in this study should be developed in the future.

Author Contributions: Conceptualization, S.K.; methodology, S.K.; validation, D.L., S.S. and D.K.; formal analysis, D.L., S.S. and S.K.; investigation, D.K.; data curation, D.K.; writing-original draft preparation, D.L. and S.K.; writing-review and editing, D.L. and S.K.; visualization, S.S.; supervision, S.K.; project administration, S.K.; funding acquisition, S.K. All authors have read and agreed to the published version of the manuscript.

Funding: This work was supported by the National Research Foundation of Korea (NRF) grant funded by the Korean government (MOE) (no. 2017R1D1A1B04033761).

Acknowledgments: The authors thank SK E\&C for providing the rebar data of the case project to verify the CWM algorithms.

Conflicts of Interest: The authors declare no conflict of interest. The funders had no role in the design of the study; in the collection, analyses, or interpretation of data; in the writing of the manuscript, or in the decision to publish the results.

\section{References}

1. International Energy Agency and the United Nations Environment Programme. 2018 Global Status Report: Towards a Zero-Emission, Efficient and Resilient Buildings and Construction sector. 2018, p. 9. Available online: https://www.worldgbc.org/sites/default/files/2018\%20GlobalABC\%20Global\%20Status\%20Report. pdf (accessed on 19 April 2020).

2. Pacheco-Torgal, F.; Cabeza, L.; Labrincha, J.; De Magalhaes, A. Eco Efficient Construction and Building Materials: Life Cycle Assessment (LCA), Eco-Labelling and Case Studies; Elsevier: Cambridge, UK, 2014; Volume 1, pp. 624-630.

3. Clark, D.; Bradley, D. Information Paper-31: Embodied Carbon of Steel Versus Concrete Buildings; Cundall Johnston \& Partners LLP: Newcastle, UK, 2013; p. 4.

4. Lee, I.J.; Yu, H.; Chan, S.L. Carbon Footprint of Steel-Composite and Reinforced Concrete Buildings, Standing Committee on Concrete Technology Annual Concrete Seminar 2016, Hong Kong, 20 April 2016; Construction Industry Council. Available online: https://www.devb.gov.hk/filemanager/en/content_971/7_Carbon_ Footprint_for_Steel_Composite_and_Reinforced_Concrete_Buildings.pdf (accessed on 22 April 2020).

5. Kim, S.K.; Kim, M.H. A Study on the development of the optimization algorithm to minimize the loss of reinforcement bars. J. Archit. Inst. Korea 1991, 7, 385-390.

6. Kim, G.H. A Study on Program of Minimizing the Loss of Re-Bar. Master's Thesis, Korea University, Seoul, Korea, 2002; pp. 8-58.

7. Porwal, A.; Hewage, K.N. Building information modeling-based analysis to minimize waste rate of structural reinforcement. J. Constr. Eng. Manag. 2012, 138, 943-954. [CrossRef]

8. Poonkodi, N. Development of software for minimization of wastes in rebar in rcc structures by using linear programming. Int. J. Adv. Res. Trends Eng. Technol. (IJARTET) 2016, 3, 1262-1267.

9. Nadoushani, Z.; Hammad, A.; Akbar Nezhad, A. A Framework for Optimizing Lap Splice Positions within Concrete Elements to Minimize Cutting Waste of Steel Bars. In Proceedings of the 33th International Symposium on Automation and Robotics in Construction (ISARC 2016), Auburn, AL, USA, 21 July 2016. [CrossRef]

10. Shahin, A.A.; Salem, O.M. Using genetic algorithms in solving the one-dimensional cutting stock problem in the construction industry. Can. J. Civ. Eng. 2004, 31, 321-332. [CrossRef] 
11. Chandrasekar, M.K.; Nigussie, T. Rebar Wastage in Building Construction Projects of Hawassa, Ethiopia. Int. J. Sci. Eng. Res. 2018, 9, 282-287.

12. Nadoushani, Z.S.M.; Hammad, A.W.; Xiao, J.; Akbarnezhad, A. Minimizing cutting wastes of reinforcing steel bars through optimizing lap splicing within reinforced concrete elements. Constr. Build. Mater. 2018, 185, 600-608. [CrossRef]

13. Zubaidy, S.S.; Dawood, S.Q.; Khalaf, I.D. Optimal utilization of rebar stock for cutting processes in housing project. Int. Adv. Res. J. Sci. 2016, 3, 189-193. [CrossRef]

14. Kim, S.K.; Hong, W.K.; Joo, J.K. Algorithms for reducing the waste rate of reinforcement bars. J. Asian Archit Build. 2004, 3, 17-23. [CrossRef]

15. 44/12 Benjaoran, V.; Bhokha, S. Trim loss minimization for construction reinforcement steel with oversupply constraints. J. Adv. Manag. Sci. 2013, 1, 313-316. [CrossRef]

16. Benjaoran, V.; Bhokha, S. Three-step solutions for cutting stock problem of construction steel bars. KSCE J. Civ. Eng. 2014, 18, 1239-1247. [CrossRef]

17. Kim, D.; Lim, C.; Liu, Y.; Kim, S. Automatic Estimation System of Building Frames with Integrated Structural Design Information (AutoES). Iranian J. Sci. Tech. Trans. Civ. Eng. 2019, 1-13. [CrossRef]

18. Hwang, J.W.; Park, C.J.; Wang, S.K.; Choi, C.H.; Lee, J.H.; Park, H.W. A Case Study on the Cost Reduction of the Rebar Work through the Bar Loss Minimization. In Proceedings of the KIBIM Annual Conference 2012, Seoul, Korea, 19 May 2012; Volume 2, pp. 67-68.

19. Khalifa, Y.; Salem, O.; Shahin, A. Cutting Stock Waste Reduction using Genetic Algorithms. In Proceedings of the 8th Annual Conference on Genetic and Evolutionary Computation, Seattle, WA, USA; 2006; pp. 1675-1680. [CrossRef]

20. Salem, O.; Shahin, A.; Khalifa, Y. Minimizing cutting wastes of reinforcement steel bars using genetic algorithms and integer programming models. J. Constr. Eng. Manag. 2007, 133, 982-992. [CrossRef]

21. Gilmore, P.C.; Gomory, R.E. A linear programming approach to the cutting-stock problem. Oper. Res. 1961, 9, 849-859. [CrossRef]

22. Nanagiri, Y.V.; Singh, R.K. Reduction of wastage of rebar by using BIM and linear programming. Int. J. Tech. 2015, 5, 329-334. [CrossRef]

23. Zheng, C.; Yi, C.; Lu, M. Integrated optimization of rebar detailing design and installation planning for waste reduction and productivity improvement. Autom. Constr. 2019, 101, 32-47. [CrossRef]

24. Zheng, C. Multi-Objective Optimization for Reinforcement Detailing Design and Work Planning on a Reinforced Concrete Slab Case. Master's Thesis, Alberta University, Edmonton, Canada, 2018. [CrossRef]

25. Zheng, C.; Lu, M. Optimized reinforcement detailing design for sustainable construction: Slab case study. Procedia Eng. 2016, 145, 1478-1485. [CrossRef]

26. Kantorovich, L.V. Mathematical methods of organizing and planning production. Manag. Sci. 1960, 6, 366-422. [CrossRef]

27. Ben Amor, H.; Valério de Carvalho, J. Cutting stock problems. In Column Generation; Springier: Boston, MA, USA, 2005; pp. 131-161. [CrossRef]

28. Cutting Stock Problem. Available online: https://en.wikipedia.org/wiki/Cutting_stock_problem (accessed on 20 April 2020).

29. Arbib, C.; Marinelli, F.; Ventura, P. One-dimensional cutting stock with a limited number of open stacks: Bounds and solutions from a new integer linear programming model. Int. Trans. Oper. Res. 2016, 23, 47-63. [CrossRef]

30. Berberler, M.; Nuriyev, U.; Yildirım, A. A Software for the one-dimensional cutting stock problem. J. King Saud Univ. Sci. 2011, 23, 69-76. [CrossRef]

31. Belov, G.; Scheithauer, G. Setup and open-stacks minimization in one-dimensional stock cutting. INFORMS J. Comput. 2007, 19, 27-35. [CrossRef]

32. Dyckhoff, H. A new linear programming approach to the cutting stock problem. Oper. Res. 1981, 29, 1092-1104. [CrossRef]

33. Feifei, G.; Lin, L.; Jun, P.; Xiazi, Z. Study of One-Dimensional Cutting Stock Problem with Dual-Objective Optimization. In Proceedings of the International Conference on Computer Science and Information Processing (CSIP), Xi'an, Shaanxi, China, 24-26 August 2012. [CrossRef]

34. Fernandez, L.; Fernandez, L.A.; Pola, C. Integer Solutions to Cutting Stock Problems. In Proceedings of the 2nd International Conference on Engineering Optimization, Lisbon, Portugal, 6-9 September 2010. 
35. Gilmore, P.C.; Gomory, R.E. A linear programming approach to the cutting-stock problem-part II. Oper. Res. 1963, 11, 863-888. [CrossRef]

36. Goulimis, C. Optimal solutions for the cutting stock problem. Eur. J. Oper. Res. 1990, 44, 197-208. [CrossRef]

37. Haessler, R.W.; Sweeney, P.E. Cutting stock problems and solution procedures. Eur. J. Oper. Res. 1991, 54, 141-150. [CrossRef]

38. Haessler, R.W. Controlling cutting pattern changes in one-dimensional trim problems. Oper. Res. 1975, 23, 483-493. [CrossRef]

39. Jahromi, M.H.; Tavakkoli, R.; Makui, A.; Shamsi, A. Solving an one-dimensional cutting stock problem by simulated annealing and tabu search. J. Ind. Eng. Int. 2012, 8, 24. [CrossRef]

40. Lin, P. Optimal Solution of One Dimension Cutting Stock Problem. Master's Thesis, Lehigh University, Bethlehem, PA, USA, 26 April 1994.

41. Roodman, G.M. Near-optimal solutions to one-dimensional cutting stock problems. Comput. Oper. Res. 1986, 13, 713-719. [CrossRef]

42. Vahrenkamp, R. Random search in the one-dimensional cutting stock problem. Eur. J. Oper. Res. 1996, 95, 191-200. [CrossRef]

43. Chen, C.; Hart, S.; Tham, W. A simulated annealing heuristic for the one-dimensional cutting stock problem. Eur. J. Oper. Res. 1996, 93, 522-535. [CrossRef]

44. Cherri, A.C.; Arenales, M.N.; Yanasse, H.H. The one-dimensional cutting stock problem with usable leftover-A heuristic approach. EUR J. OPER RES. 2009, 196, 897-908. [CrossRef]

45. Cui, Y.; Zhao, X.; Yang, Y.; Yu, P. A heuristic for the one-dimensional cutting stock problem with pattern reduction. Proc. Inst. Mech. Eng. Part B: J. Eng. Manuf. 2008, 222, 677-685. [CrossRef]

46. Gradišar, M.; Kljajić, M.; Resinovič, G.; Jesenko, J. A sequential heuristic procedure for one-dimensional cutting. Eur. J. Oper. Res. 1999, 114, 557-568. [CrossRef]

47. Poldi, K.C.; Arenales, M.N. Heuristics for the one-dimensional cutting stock problem with limited multiple stock lengths. Comput. Oper. Res. 2009, 36, 2074-2081. [CrossRef]

48. Wang, Z.; Rao, G. A multi-stage genetic algorithm for one-dimensional cutting stock problems with one stock material length. J. Syst. Sci. Inf. 2005, 3, 643-651. [CrossRef]

49. KICT (Korea Institute of Construction Technology). The Environmental Load Unit Composition and Program Development for LCA of Building, The Second Annual Report of the Construction Technology R\&D Program. 2004. Available online: http://www.ndsl.kr/ndsl/search/detail/report/reportSearchResultDetail.do? cn=TRKO201000018952 (accessed on 28 May 2020).

50. CDP Worldwide. Carbon Pricing Connect. Available online: https://www.cdp.net/en/climate/carbon-pricing/ carbon-pricing-connect (accessed on 29 May 2020). 